\title{
Effect of process parameters on coating composition of cathodic-plasma-electrolysis-treated copper
}

\author{
ASIYEH HABIBI ${ }^{1}$, S MOHAMMAD MOUSAVI KHOIE ${ }^{1, *}$, FARZAD MAHBOUBI ${ }^{1}$ and \\ MUSTAFA URGEN ${ }^{2}$ \\ ${ }^{1}$ Department of Mining and Metallurgical Engineering, Amirkabir University of Technology, Tehran 15875-4413, Iran \\ ${ }^{2}$ Department of Metallurgical and Materials Engineering, Istanbul Technical University, Istanbul 34469, Turkey
}

MS received 2 March 2016; accepted 4 July 2016

\begin{abstract}
Cathodic plasma electrolysis is a novel technique to form nanostructured layers on metallic surfaces by application of high voltage in a suitable aqueous electrolyte. In the present study, copper is treated by plasma electrolysis in $50 \mathrm{vol} \%$ ethanol electrolyte and coatings comprising carbon nanostructure and copper oxide are formed on the copper. The effect of some process parameters such as electrical conductivity, volume and temperature of electrolyte and ratio of anode to cathode surface area on current-voltage behaviour and subsequently coating compositions are investigated at $150 \mathrm{~V}$ deposition voltage. The composition and morphology of these coatings are characterized by X-ray diffraction, Raman spectroscopy and scanning electron microscopy. Different current-voltage behaviours, temperatures of substrate and the contents and energies of radicals and ions around the substrate by changes in the mentioned parameters cause different compositions from 100 vol\% copper oxide to different ratios of copper oxide to carbon, the structure changing from amorphous to graphitic structure in carbon and amorphous to cubic morphology in copper oxide on the substrate. Therefore, the understanding of cathodic plasma electrolysis can be developed.
\end{abstract}

Keywords. Plasma electrolytic deposition; current density; current-voltage behaviour; copper oxide film; carbon nanostructure film.

\section{Introduction}

Plasma electrolysis is an atmospheric pressure plasma treatment that has recently attracted the attention of researchers working on surface modification [1]. This electrochemical method is realized by the application of high voltage between the electrodes that are introduced into an electrolyte that possesses the species that has the ability to modify the surface [2]. Depending on the polarity of the working electrode, the plasma electrolysis process can be categorized to anodic or cathodic treatments [3]. For the anodic plasma process, surface passivation of the working electrode can lead to the growth of oxide film and it can be named micro-arc oxidation (MAO) or plasma electrolytic oxidation (PEO) [4]. On the other hand, when the substrate is cathodically polarized (cathodic plasma electrolysis, CPE [5]) it becomes possible to produce complex coating such as carbon structures, oxides $[6,7]$, titanium, molybdenum, zinc and zinc-aluminium on metallic substrates [8]. Although the PEO process has been the subject of numerous studies and found industrial applications, the CPE process is relatively new and not well established when compared with PEO. The results of the studies have shown that the composition of the electrolyte [9], electrolyte concentration [10], voltage [11], mode of applied

\footnotetext{
*Author for correspondence (mmousavi@aut.ac.ir, a_habibi@aut.ac.ir)
}

current, current density, electric field, solution temperature, treatment time [12], ratio of anode to cathode surface area and distance between electrodes [13] are the parameters to be controlled for the production of high-quality coatings.

Current density is one of the most important parameters both in CPE [5] and PEO [14] processes because of its direct relation to the surface temperature. Therefore, changes in coating structure, composition and morphology are possible by controlling the current density of the substrate. It is known that in the CPE process, higher current density indicates movement of more particles from the electrolyte to the high-temperature cathode and increases the growth rate of the film $[10,15]$. The current density is not only a function of applied potential but also electrical conductivity, volume and temperature of electrolyte and ratio of anode to cathode surface area.

In the literature there are no systematic studies that investigate the combined role of the aforestated parameters on the coating structure. The aim of this study is to systematically investigate the effect of the aforestated parameters on the structure and morphology of the CPE-modified surface of copper. To achieve this aim, the copper-ethanol system has been selected (ethanol was selected as electrolyte because of its clearness and copper was selected as substrate since carbon does not have any solubility in copper and does not form any compounds with copper) and the processparameter-dependent current-voltage behaviours have been 
investigated. Due to the effect of current density and voltage variations on both substrate temperature and transferring ions and radicals content from electrolyte to the substrate, the changes of coating composition have been studied from 100 vol\% copper oxide coating to a coating comprising different ratios of copper oxide to amorphous carbon.

\section{Experimental}

The electrical conductivity, volume and temperature of electrolyte and also ratio of anode to cathode surface area (by increasing cathode surface area) were selected as the CPE process variables for investigating their effect on current density and coating structure. Figure 1 illustrates a schematic of the test design. Voltage was applied to the electrodes gradually $\left(\mathrm{d} V / \mathrm{d} t \sim 1 \mathrm{~V} \mathrm{~s}^{-1}\right.$ ) up to $150 \mathrm{~V}$ and a thin film was formed on the cathode under the condition of $150 \mathrm{~V}$ for $10 \mathrm{~min}$ in an aqueous solution containing $50 \mathrm{vol} \%$ ethanol. The current fluctuation was monitored during the rise of voltage. Sodium hydroxide was added to increase the electrical conductivity of the solution. Rectangular specimens

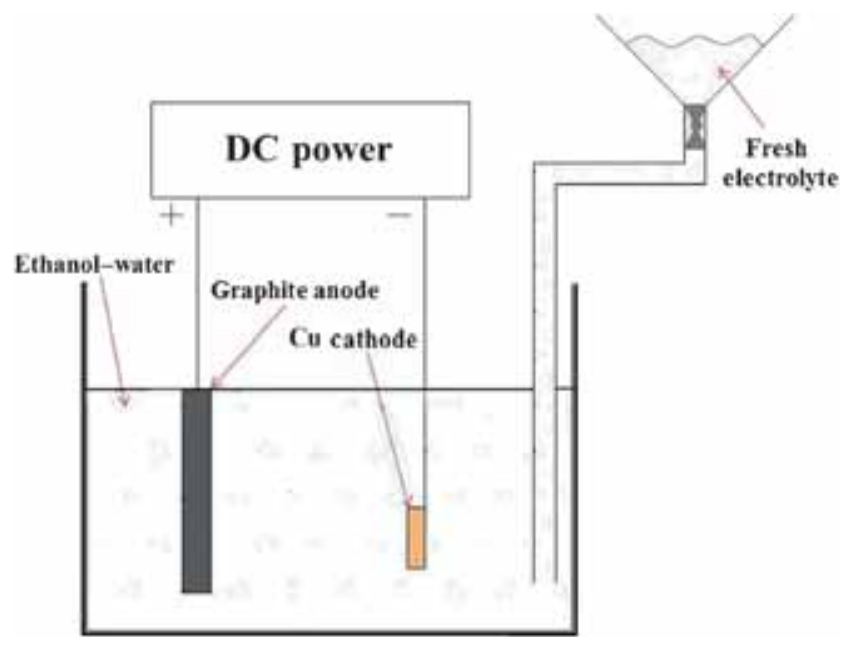

Figure 1. Schematic illustration of the CPE system. The cathode size is smaller than the anode to concentrate the current density and create the arc discharge around the cathode. of copper were used as substrate with $1 \mathrm{~cm}$ distance to the counter electrode (the $\mathrm{Cu}$ exposure surface area is presented in table 1). The $\mathrm{Cu}$ plate was mechanically polished with a 1200 -grit abrasive paper. The average roughness of the substrates was about $250 \mathrm{~nm}$. The anode was graphite plate, to avoid any deposition of anodic metal on the cathode, with an exposure surface area of $20 \mathrm{~cm}^{2}$. The temperature of the solution increased rapidly by applied voltage up to boiling temperature. Thus, fresh electrolyte was added during the process to keep the same solution volume. Table 1 shows other experimental conditions for evaluating the current density in the CPE process.

The surface morphology and roughness of the deposited films were characterized by employing scanning electron microscopy (SEM) and field emission scanning electron microscopy (FESEM) at $15 \mathrm{kV}$ and an optical profilometer (Wyko NT1100, Vecco, Switzerland), respectively. Raman spectra were acquired using a $632.8 \mathrm{~nm} \mathrm{He}-\mathrm{Ne}$ laser with $3 \mathrm{~mW}$ laser power (LabRam 800, Horiba Scientific, Jobin Yvon, France). The phase composition of the deposited films was investigated by X-ray diffraction (XRD) with a $\mathrm{Cu} \mathrm{K}_{\alpha}$ radiation source and grazing angle of $0.5^{\circ}$ over a $2 \theta$ range of $20-80^{\circ}$.

\section{Results and discussion}

The plasma electrolytic deposition (PED) process has been described by many researchers. The time-dependent currentvoltage behaviour during this process has been presented for both of the PEO and CPE processes [4]. The physicochemical analysis of the $\mathrm{CPE}$ process was described theoretically and experimentally by Gupta et al [1] and Paulmier et al [16]. The understanding of the CPE process can be developed by the study of some process parameters on currentvoltage behaviour and subsequently coating composition in this paper.

\subsection{Effect of electrical conductivity of the electrolyte}

The effect of electrolyte conductivity was studied using three different concentrations of $\mathrm{NaOH}$ in ethanol. Figure 2 shows

Table 1. Experimental condition for evaluating current density in the CPE process.

\begin{tabular}{lcccc}
\hline $\begin{array}{l}\text { Sample } \\
\text { number }\end{array}$ & $\begin{array}{c}\mathrm{NaOH} \text { content } \\
(\mathrm{wt} \%)\end{array}$ & $\begin{array}{c}\text { Electrolyte } \\
\text { volume }\left(\mathrm{cm}^{3}\right)\end{array}$ & $\begin{array}{c}\text { Electrolyte } \\
\text { temperature }\left({ }^{\circ} \mathrm{C}\right)\end{array}$ & $\begin{array}{c}\text { Cathode } \\
\text { surface }\left(\mathrm{cm}^{2}\right)\end{array}$ \\
\hline $\mathrm{Cu} \mathrm{1}$ & 0.005 & 150 & $\mathrm{RT}$ & 0.25 \\
$\mathrm{Cu} \mathrm{2}$ & 0.010 & 150 & $\mathrm{RT}$ & 0.25 \\
$\mathrm{Cu} \mathrm{3}$ & 0.020 & 150 & $\mathrm{RT}$ & 0.25 \\
$\mathrm{Cu} \mathrm{4}$ & 0.020 & 300 & $\mathrm{RT}$ & 0.25 \\
$\mathrm{Cu} \mathrm{5}$ & 0.020 & 300 & 60 & 0.25 \\
$\mathrm{Cu} \mathrm{6}$ & 0.020 & 300 & $5^{*}$ & 0.25 \\
$\mathrm{Cu} \mathrm{7}$ & 0.020 & 150 & $\mathrm{RT}$ & 1.5 \\
\hline
\end{tabular}

*Cooled electrolyte during the CPE process. 


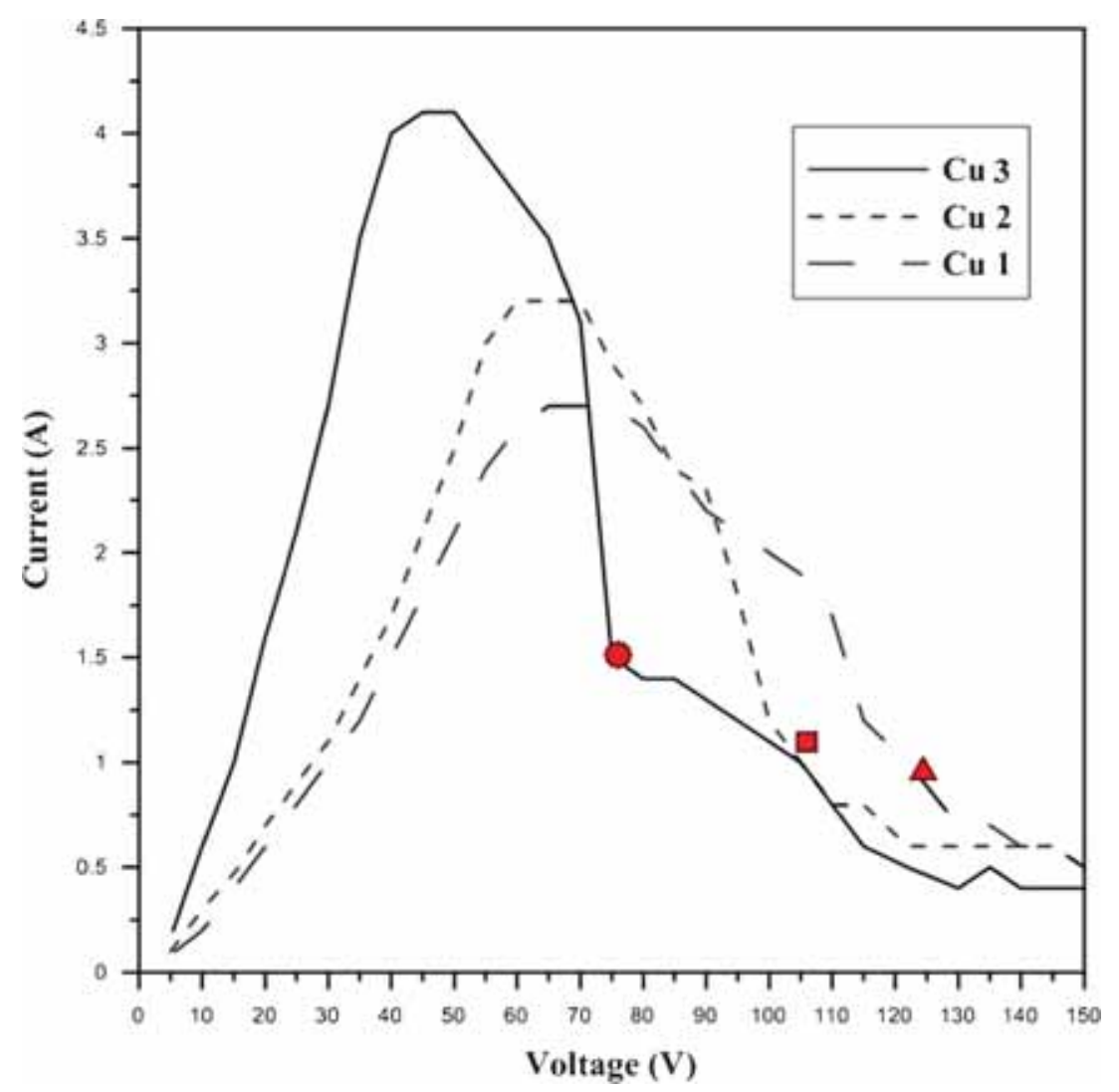

Figure 2. The effect of electrolyte conductivity on current variation with rising voltage. The breakdown current and voltage of each sample are shown by symbols.

the current-voltage behaviour of the three samples labelled as $\mathrm{Cu} 1-3$ in table 1 . It can be seen that the current increases linearly with voltage in the first stage for all samples. Then, the current saturates and reduces to about $0.5 \mathrm{~A}$ at $150 \mathrm{~V}$. According to Ohm's law, in the first stage, an increase of electrical conductivity of the solution leads to a higher value of the current and consequently, according to the Joule effect, the temperature of the cathode and electrolyte at this specific voltage range increases with increasing $\mathrm{NaOH}$ content. Therefore, bubbling starts at the lower voltages. Thus, a higher value of the saturated current is observed at a lower voltage range for $\mathrm{Cu} 3$. Hence, it can be stated that at this stage, the current density of the substrate is increased by using the electrolyte with higher electrical conductivity. After this stage, the bubble envelope gets thicker with an increase in voltage, and the current reduces because of the high electrical resistance of this gas envelope. The breakdown voltage and current of each sample are shown by symbols in figure 2. Thus, the start of breakdown occurred at a lower voltage and higher current in the sample labelled $\mathrm{Cu} 3$. The current density of all samples has approximately the same value during the deposition at $150 \mathrm{~V}$. Our observations showed that the current density of $\mathrm{Cu} 1$ and $\mathrm{Cu} 2$ reduced slightly for voltage higher than $150 \mathrm{~V}$, whereas it presented a constant value for $\mathrm{Cu} 3$.

The breakdown in the gas envelope leads to an acceleration of positive ions and transfer of their kinetic energy to the cathode surface [1]. This energy can be increased by a more intense breakdown due to a higher voltage interval between the deposition voltage $\left(V_{\mathrm{d}}\right)$ and breakdown voltage $\left(V_{\mathrm{b}}\right)$. These intense discharges continued on the substrate during deposition time. Thus, in spite of the same constant coating voltage and current density in all of the three samples, more positive ions and radicals were transferred to the substrate of $\mathrm{Cu} 3$ and increased the substrate temperature by transferring more kinetic energy. Figure 3 shows the Raman spectra of these samples. The Gaussian fitting of the broad band in the frequency range of $400-700 \mathrm{~cm}^{-1}$ shows three bands at about 410,530 and $580 \mathrm{~cm}^{-1}$, which are related to cuprous oxide $\left(\mathrm{Cu}_{2} \mathrm{O}\right)[17,18]$, and another band at $620 \mathrm{~cm}^{-1}$, which is related to cupric oxide ( $\mathrm{CuO})$ [19].

Although the presence of hydrogen in the vicinity of the cathode reduces the oxide production on the $\mathrm{Cu}$ substrate [20], the metal oxide and hydroxide film precipitates on cathode surface from decomposition products of the electrolyte by current heating or bubbling formation around the cathode [21]. Therefore, some parts of this oxide layer are formed before breakdown on the cathode surface. When the breakdown in the gas envelope results in plasma discharges, ethanol is further decomposed into more radials and ions [22]:

$$
\begin{aligned}
& \mathrm{CH}_{3} \mathrm{CH}_{2} \mathrm{OH} \rightarrow \mathrm{CH}_{3} \mathrm{CH}_{2}^{\bullet}+\mathrm{OH}^{\bullet} \\
& \mathrm{CH}_{3} \mathrm{CH}_{2} \mathrm{OH} \rightarrow{ }^{\bullet} \mathrm{CH}_{2} \mathrm{CH}_{2} \mathrm{OH}+\mathrm{H}^{\bullet} \\
& \mathrm{CH}_{3} \mathrm{CH}_{2} \mathrm{OH} \rightarrow{ }^{\bullet} \mathrm{CH}_{3}+{ }^{\bullet} \mathrm{CH}_{2} \mathrm{OH}
\end{aligned}
$$




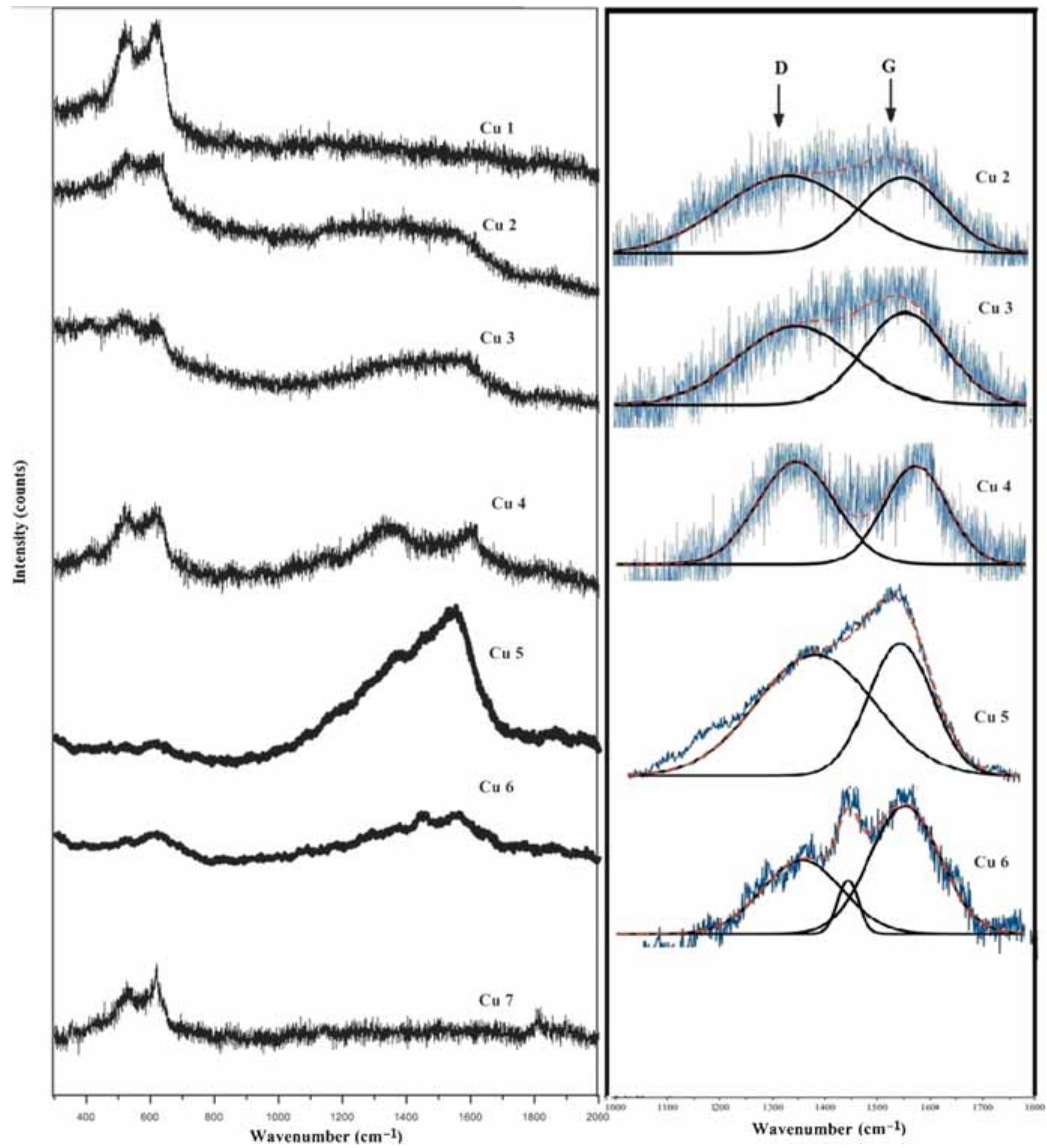

Figure 3. The effect of different CPE process parameters on Raman spectra of the $\mathrm{Cu} 1-7$ samples and the Gaussian fitting of D and G bands. The detailed experimental conditions of each sample are presented in table 1.

Hydrocarbon radicals form carbon coating on cathode surface, active hydrogen ions saturate the dangling bonds of carbon, and oxygen and hydroxide ions form copper oxides and hydroxide on the cathode surface [23]. The copper hydroxides can be transformed into oxides at a local high temperature by discharges [6]. Therefore, a composite film of amorphous carbon, $\mathrm{CuO}$ and $\mathrm{Cu}_{2} \mathrm{O}$ is prepared (oxide production before and after breakdown was proven by studying the two sample coatings without breakdown and with applied voltage in this process, respectively). At higher voltage, this oxide layer is partly removed by chemical reaction with hydrogen and mechanical energy of breakdown [1]. Therefore, the intensity 
of the oxide bands in the Raman spectrum is reduced in $\mathrm{Cu}$ 3 with a higher $V_{\mathrm{b}}$ and $V_{\mathrm{d}}$ interval. As a result of intense discharges in the higher $\mathrm{NaOH}$ content electrolyte, more carbon radicals are transferred from the electrolyte to $\mathrm{Cu}$ substrate for producing carbon coating. The observation of the Gaussian-fitted Raman bands in the wavenumber range of $1300-1700 \mathrm{~cm}^{-1}$ confirmed the presence of carbon on the substrate (figure 3). Calculated fitting parameters of D and $\mathrm{G}$ bands of $\mathrm{Cu} 2,3$ samples are listed in table 2. Therefore, electrical conductivity of the electrolyte can be effective on the coating structure by changing the content and energy of transferring ions and radicals to the substrate. The

Table 2. Gaussian fitting results of Raman spectra of the $\mathrm{Cu} 2-6$ samples. The detailed experimental conditions of each sample are presented in table 1 .

\begin{tabular}{lccccc}
\hline & $\begin{array}{c}\mathrm{G} \text { position } \\
\text { Sample }\end{array}$ & $\begin{array}{c}\text { D position } \\
\left(\mathrm{cm}^{-1}\right)\end{array}$ & \multicolumn{3}{c}{$\mathrm{FWHM}_{\mathrm{G}}$} \\
\hline $\mathrm{Cu} 2$ & 1551 & 1330 & 1.02 & 190 & 1.5 \\
$\mathrm{Cu} \mathrm{3}$ & 1562 & 1355 & 0.90 & 187 & 0.86 \\
$\mathrm{Cu} 4$ & 1582 & 1351 & 1.04 & 139 & 1.32 \\
$\mathrm{Cu} \mathrm{5}$ & 1554 & 1384 & 0.92 & 142 & 0.1 \\
$\mathrm{Cu} 6$ & 1559 & 1360 & 0.57 & 150 & 0.57 \\
\hline
\end{tabular}

composition ratio of copper oxide to amorphous carbon on $\mathrm{Cu}$ substrate can be measured by its Raman bands intensity. The Raman results (table 2) show that the copper oxide content reduces from 100 vol\% on $\mathrm{Cu} 1$ to 60 and 45 vol\% on $\mathrm{Cu}$ 2 and $\mathrm{Cu} 3$, respectively.

The XRD patterns of $\mathrm{Cu} 1$ are shown in figure 4 . Three peaks located at $43.2,50.4$ and $74.1^{\circ}$ are related to the $\mathrm{Cu}$ substrate. Two weak peaks at 36.3 and $42.3^{\circ}$ show the formation of $\mathrm{Cu}_{2} \mathrm{O}$ and $\mathrm{CuO}$ on the $\mathrm{Cu}$ substrate, respectively.

Figure 5a-c shows the SEM images of these samples. More uniform morphology and smaller voids are obvious on the surface of $\mathrm{Cu} 3$. Smaller sparks on the surface and higher temperature of the substrate (because of intense discharges) lead to spot melting of the substrate and a slight decrease in roughness of the surface. The surface roughness shows an approximately similar value in samples $\mathrm{Cu}$ 1-3 (table 3).

\subsection{Effect of electrolyte volume}

Using a higher volume of electrolyte with a constant inter-electrode distance can be effective on current-voltage behaviour in the CPE process. The variations of the current with an increase in voltage on using 150 and $300 \mathrm{~cm}^{3}$ of electrolyte are shown in figure 6 . These samples are labelled $\mathrm{Cu}$ 3 and 4, respectively. According to Ohm's law, for the same

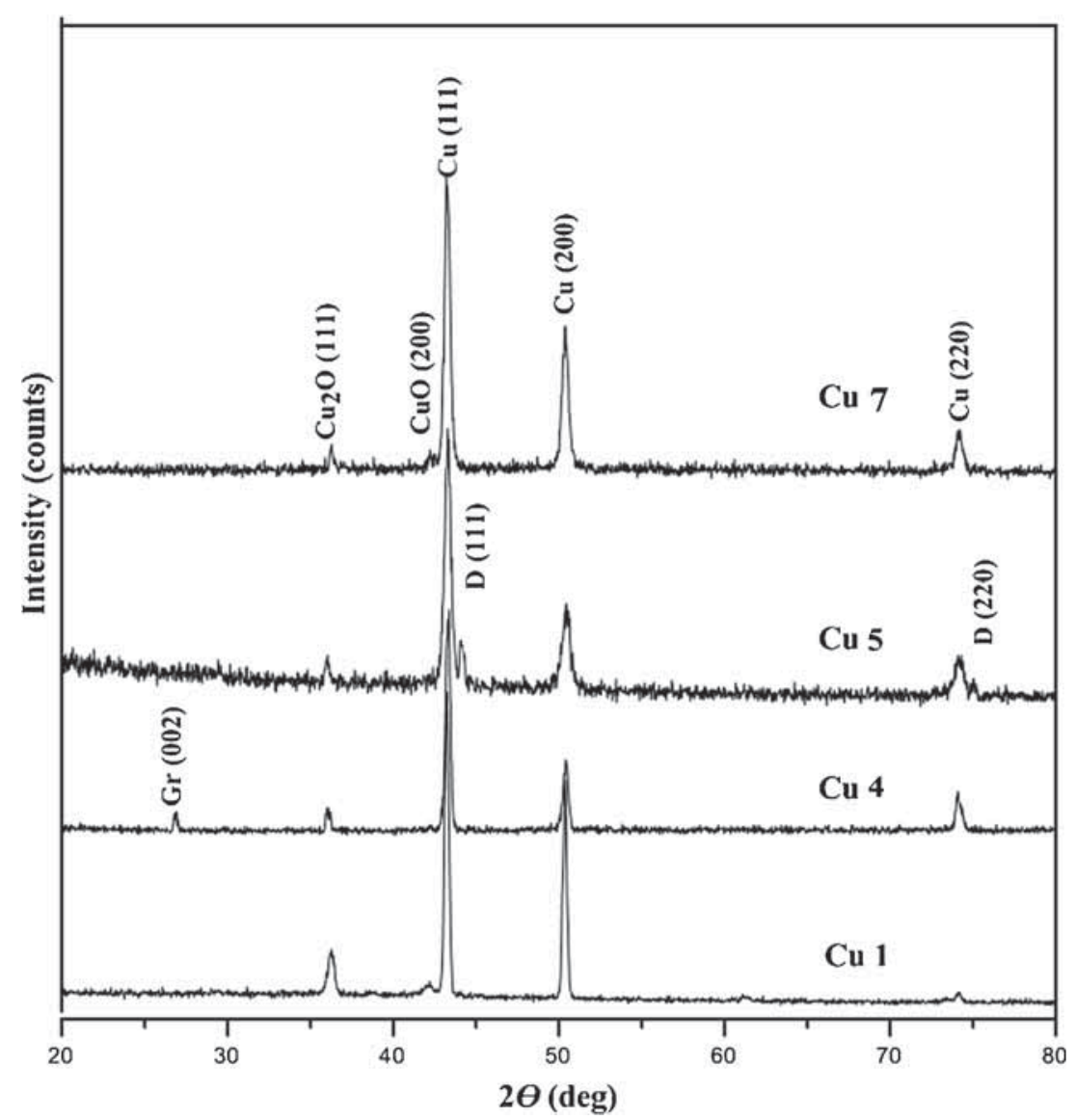

Figure 4. The XRD patterns of $\mathrm{Cu} 1,4,5$ and 7 deposited films on $\mathrm{Cu}$ substrate: $\mathrm{Gr}$ (graphite), $\mathrm{D}$ (diamond), $\mathrm{Cu}_{2} \mathrm{O}$ (cuprous oxide), $\mathrm{CuO}$ (cupric oxide) and $\mathrm{Cu}$ (copper). 

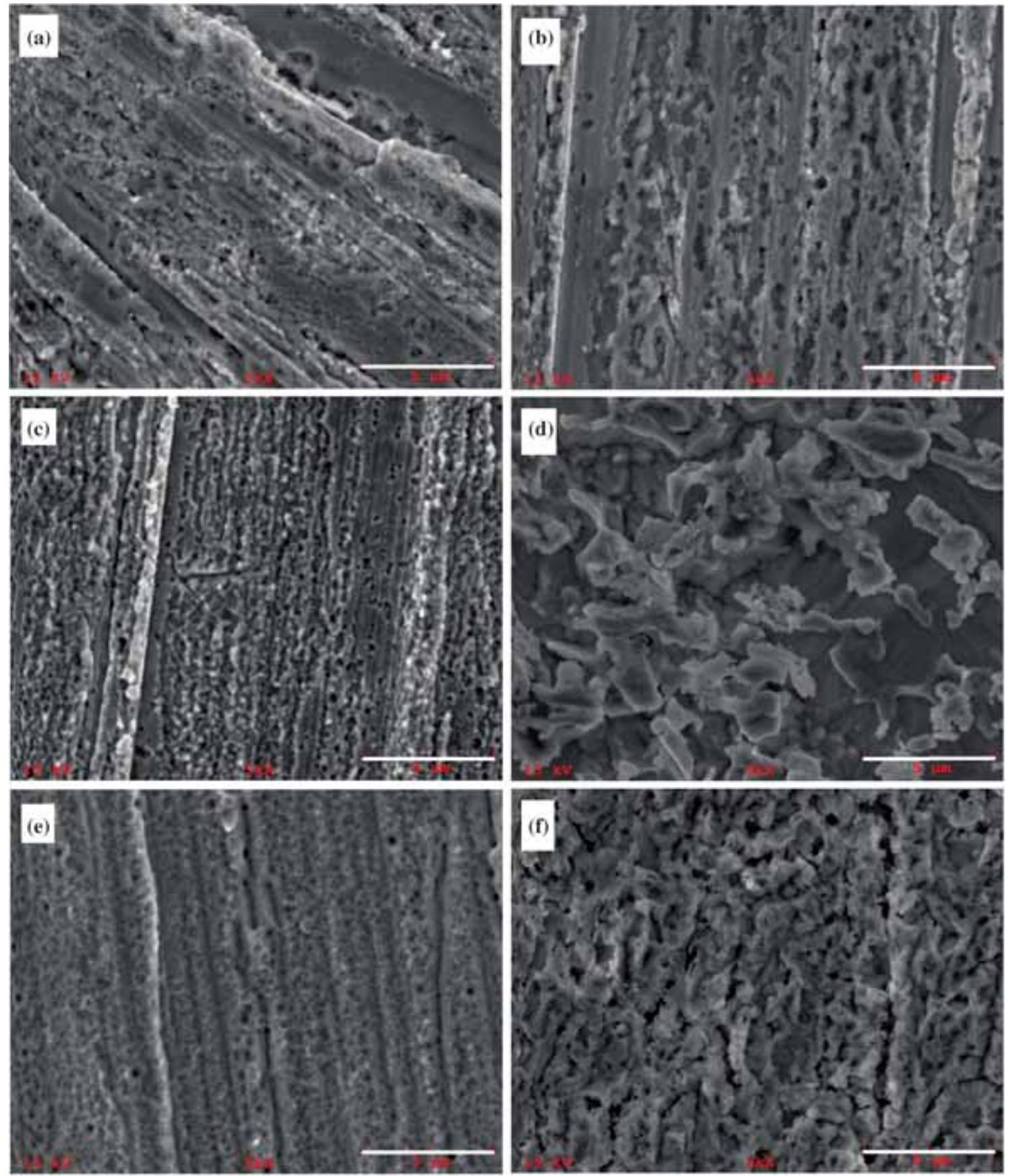

Figure 5. The SEM images of (a) $\mathrm{Cu}$ 1, (b) $\mathrm{Cu} 2$, (c) $\mathrm{Cu} 3$, (d) $\mathrm{Cu} 4$, (e) $\mathrm{Cu} 5$ and (f) $\mathrm{Cu} 6$ surface by changes of the CPE process parameters. The detailed experimental conditions of each sample are presented in table 1. Scale bars: $5 \mu \mathrm{m}$.

Table 3. The roughness results of the $\mathrm{Cu} 1-7$ coatings.

\begin{tabular}{lccccccc}
\hline Sample & $\mathrm{Cu} 1$ & $\mathrm{Cu} 2$ & $\mathrm{Cu} 3$ & $\mathrm{Cu} 4$ & $\mathrm{Cu} 5$ & $\mathrm{Cu} 6$ & $\mathrm{Cu} 7$ \\
Roughness $(\mu \mathrm{m})$ & 0.60 & 0.58 & 0.57 & 0.40 & 0.52 & 0.55 & 0.42
\end{tabular}

electrolyte with similar electrical conductivity, the currentvoltage curves of these samples match in the first stage. The bulk electrolyte temperature reaches the vapourization temperature and makes the bubble envelope in shorter time using a lower volume of electrolyte. Thus, the insulating bubbles around the cathode do not allow a further rise of the current and as in figure $6, \mathrm{Cu} 3$ shows that the current peak is observed at a lower voltage on using the lower volume of the electrolyte. The temperature increment of a higher volume electrolyte needs a higher current, which occurs at a higher voltage value. Thus, the breakdown around the cathode occurs at a higher current and voltage for $\mathrm{Cu} 4$ and shows a higher value of current density at $150 \mathrm{~V}$. With a higher current density, the bulk temperature of substrate rises 


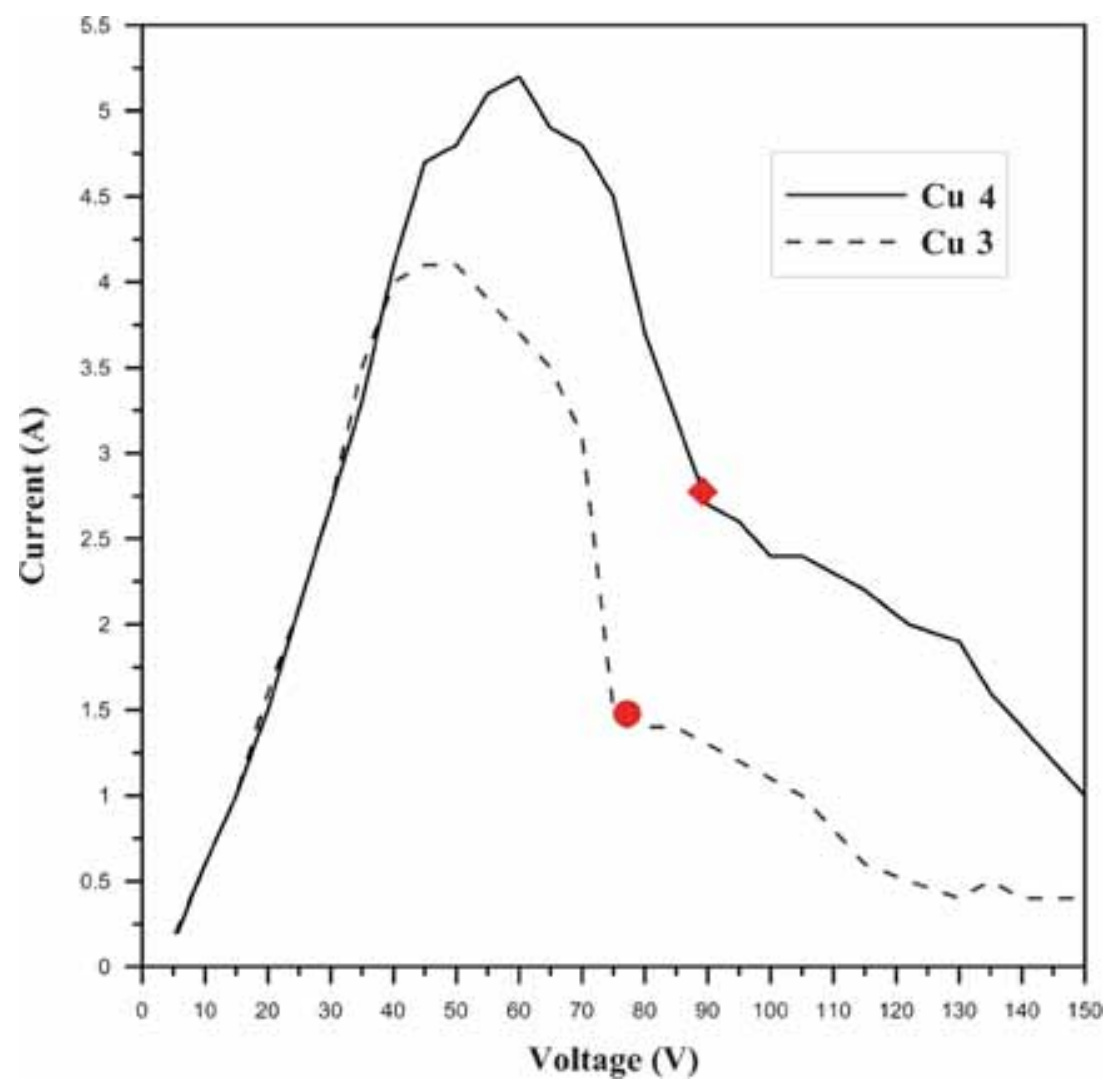

Figure 6. The effect of electrolyte volume on current variation with rising voltage. The breakdown current and voltage of each sample are shown by symbols.

in $\mathrm{Cu} 4$, and causes formation of graphitic carbon coating on $\mathrm{Cu}$ substrate.

Figure 3 shows the Raman results of these sample coatings. The Raman observations suggest that the D $\left(1351 \mathrm{~cm}^{-1}\right)$ and $\mathrm{G}\left(1582 \mathrm{~cm}^{-1}\right)$ bands of $\mathrm{Cu} 4$, which are related to carbon structures, are detected separately. The separate $\mathrm{D}$ and $\mathrm{G}$ bands and reduction of $\mathrm{FWHM}_{\mathrm{G}}$ are the signs of conversion of amorphous carbon to the crystallite graphite structure [24]. According to the three-stage 'ordering trajectory' of Ferrari and Robertson [25], an increase in the $\mathrm{G}$ band position and $I_{\mathrm{D}} / I_{\mathrm{G}}$ of $\mathrm{Cu} 4$ over those of $\mathrm{Cu} 3$ shows an increase in the $\mathrm{sp}^{2}$ bonds for changes in the carbon structure from amorphous carbon to nanocrystallite graphite (stage 2 of ordering trajectory). As the $V_{\mathrm{d}}$ and $V_{\mathrm{b}}$ interval is almost the same, the energy and amounts of the transferring radicals and ions to the substrate are approximately the same in both samples. Thus, using a higher volume of electrolyte is effective in the coating structure by increasing the current density and substrate temperature. The concomitant increase of substrate temperature by current density and high amount of radicals and ions causes the graphite $(43 \mathrm{vol} \%)$ and copper oxides ( $57 \mathrm{vol} \%)$ structures coating formation.

The XRD pattern of $\mathrm{Cu} 4$ is shown in figure 4 . The evidence of graphite and $\mathrm{Cu}_{2} \mathrm{O}$ peak at 26.8 and $36.1^{\circ}$, respectively, confirms the Raman spectroscopy results. The SEM image of $\mathrm{Cu} 4$ (figure 5d) shows different morphologies and smoother coating on the surface of this sample (table 3 ).
The thicker coating with flaky morphology on $\mathrm{Cu}$ surface can cover the rough surface of CPE-processed copper.

\subsection{Effect of electrolyte temperature}

As revealed in Section 3.2, the importance of electrolyte temperature and, consequently, the cooling of electrolyte are seen in the CPE process. The effect of electrolyte temperature has been studied for the PEO process by some researchers [26]. It is obvious that the coating formation is affected by the electrolyte temperature during the plasma electrolytic deposition. Despite the more rapid increment of the current by a rise in voltage in the first stage on heating the electrolyte up to $60^{\circ} \mathrm{C}$, figure 7 shows a lower saturated current for $\mathrm{Cu} 5$. The vapourization and bubbling around the substrate occur at the lower voltage on using electrolyte at higher temperature. Thus, the trend of rising current is stopped by rapid formation of the electrically resistant vapour envelope around copper. At a lower voltage of the plateau current, the breakdown is observed at a lower voltage for $\mathrm{Cu} 5$. According to the equation that is presented by Paulmier et al [16], the breakdown voltage strongly depends on the pressure and bubble diameter. When the cathode is covered by bubbles with smaller diameter, the breakdown occurs sooner. Lower thermal gradient in bulk electrolyte and vicinity of the cathode leads to formation of bigger bubbles. This bubble size decreases the rate of voltage rise from bubbling to breakdown 


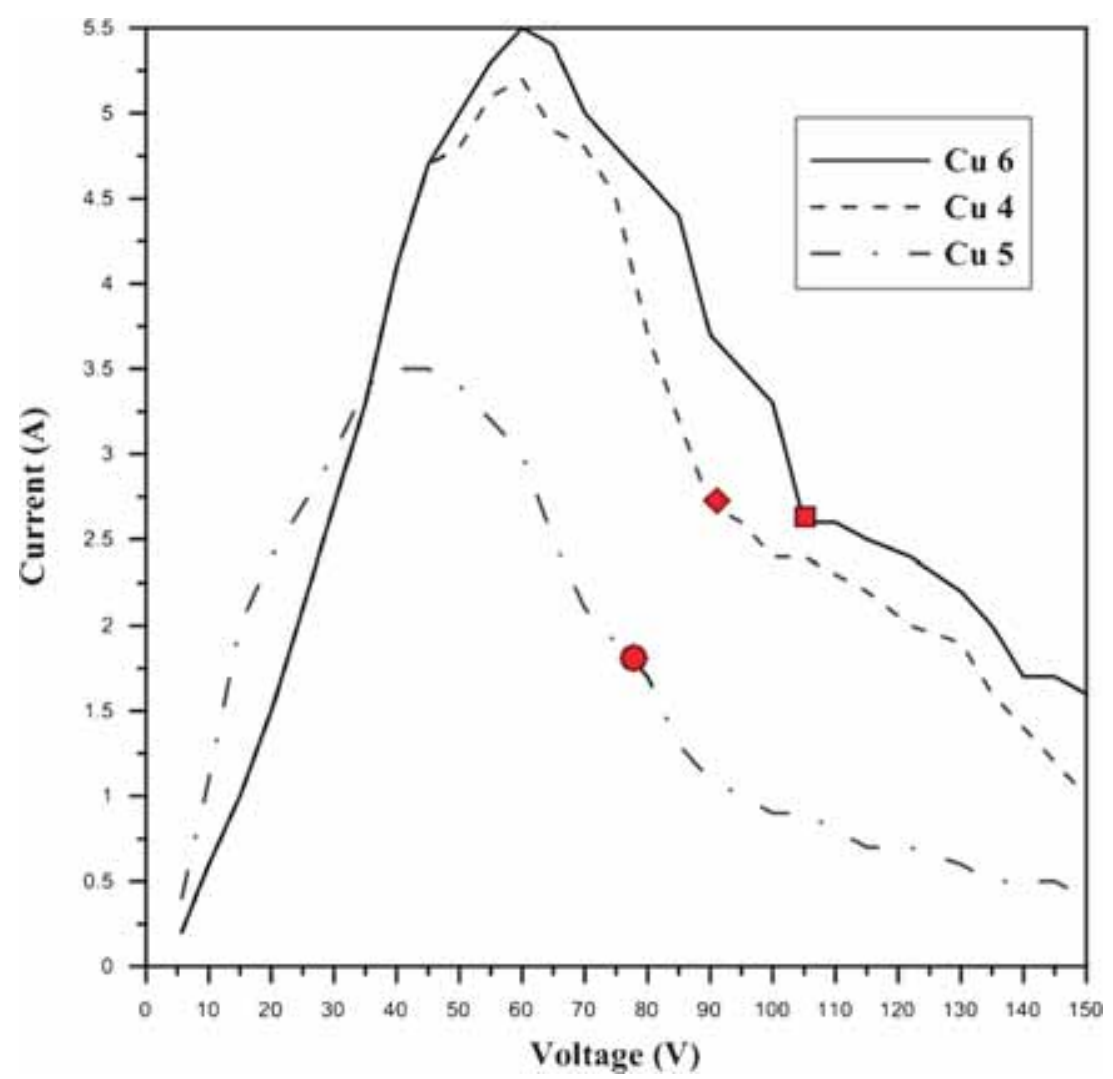

Figure 7. The effect of electrolyte temperature on current variation by rising voltage. The breakdown current and voltage of each sample are shown by symbols.

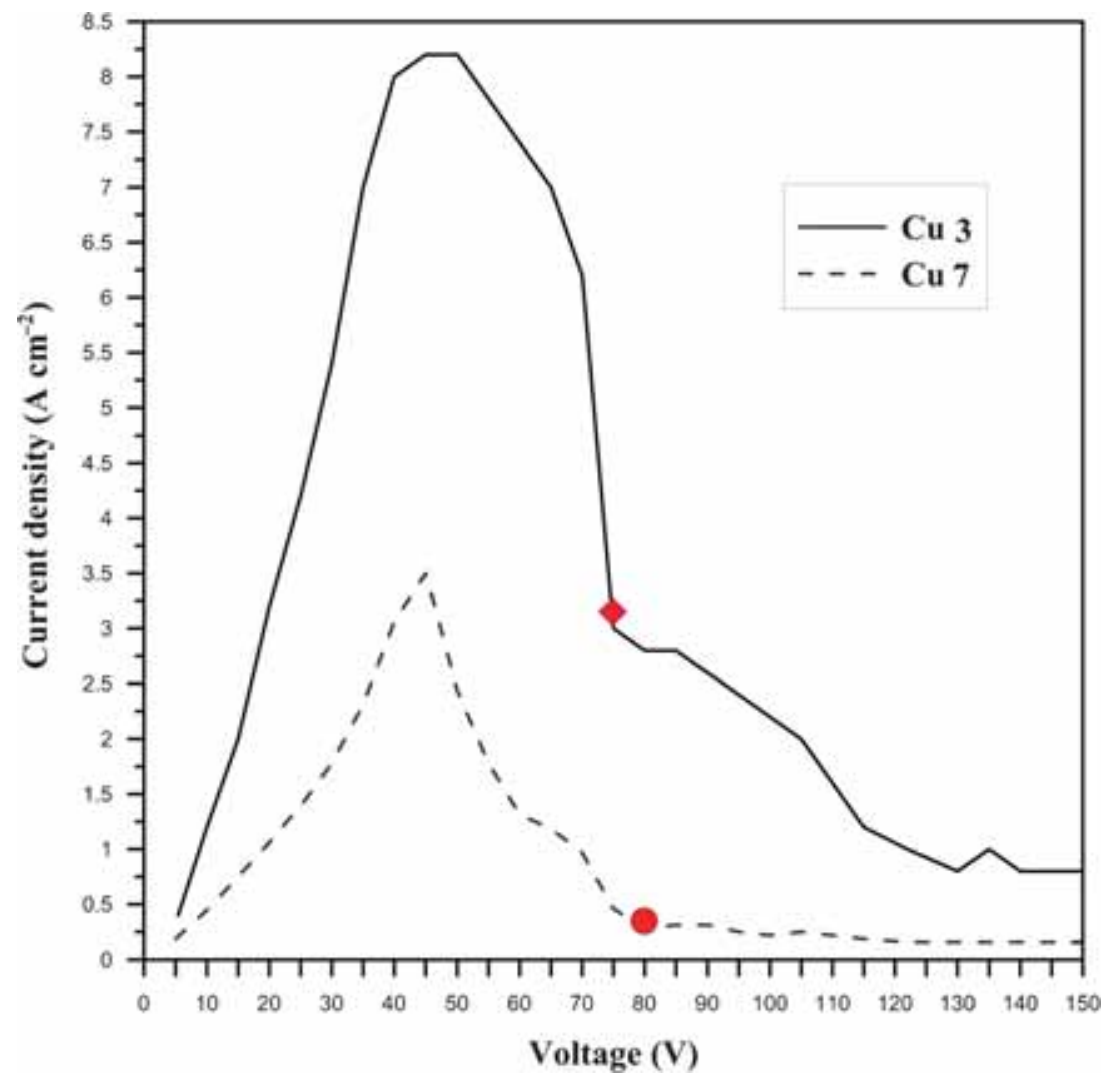

Figure 8. The effect of anode to cathode surface area on current density variation by rising voltage. The breakdown current and voltage of each sample are shown by symbols. 
on $\mathrm{Cu} 5$ [27]. Low current density at coating voltage (150 V) and suitable interval of $V_{\mathrm{b}}-V_{\mathrm{d}}$ cause formation of diamondlike carbon (99.9 vol\%) and a slight copper oxide $(0.09$ vol\%) coating on $\mathrm{Cu} 5$. The rate of oxidation reduces because of temperature reduction of the substrate (lower current density) [28] and mechanical energy of intense discharges on copper surface. The Raman results show more intense $D$ and $G$ bands than oxide bands. Compared with $\mathrm{Cu} 4$, the $\mathrm{sp}^{2}$ bands of carbon coating are reduced in $\mathrm{Cu} 5$ (according to amorphization trajectory of Ferrari and Robertson [25,29]). The XRD pattern of $\mathrm{Cu} 5$ is presented in figure 4 and shows two weak peaks at 44.2 and $75.1^{\circ}$, which can be related to the diamond structure. The SEM image of this coating is shown in figure $5 \mathrm{e}$.

Unlike electrolyte heating, the peak of the current is observed at a higher voltage in cooling electrolyte during the process, which leads to further rise of current density. The electrolyte can be cooled by circulating the cooling liquid around the process cell, which is a preferred way to cool the electrolyte [5]. Figure 7 shows a higher voltage of breakdown and current density of the substrate at $150 \mathrm{~V}$ for $\mathrm{Cu}$ 6. The cooling of electrolyte during the CPE process causes higher current requirement of the system for bubbling around copper. Thus, the saturation current will be increased. The intensities of both carbon and oxide bands in the Raman spectrum of the $\mathrm{Cu} 6$ coating are lower than those of $\mathrm{Cu} 4$, which is related to coating thickness. The current density and substrate temperature of $\mathrm{Cu} 6$ are suitable for graphitic structure forming on the $\mathrm{Cu}$ substrate, but reduction in the $V_{\mathrm{b}}-V_{\mathrm{d}}$ interval causes movement of the lower content of ions and radicals with lower energy to the substrate. Amorphous carbon formation is more dominant than that of the graphitic structure because of the low concentration of carbon ions on the $\mathrm{Cu} 6$ surface. The measured composition ratio of copper
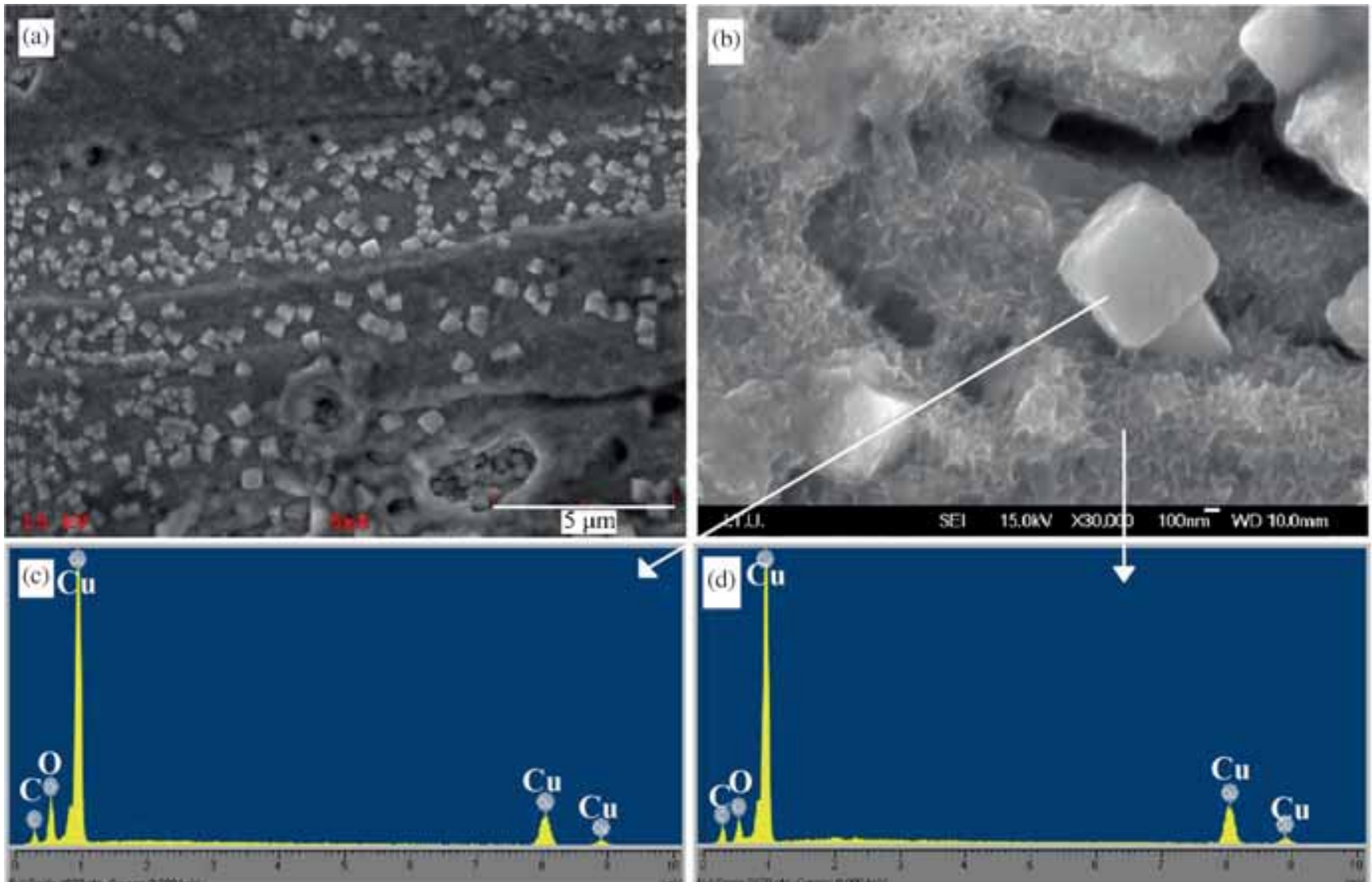

(e)

\begin{tabular}{l|l|l}
\hline Element & Weight $\%$ & Atomic\% \\
\hline $\mathrm{C}$ & 10.15 & 28.36 \\
$\mathrm{O}$ & 15.40 & 32.30 \\
$\mathrm{Cu}$ & 74.46 & 39.34 \\
\hline
\end{tabular}

(f)

\begin{tabular}{l|l|l}
\hline Element & Weight $\%$ & Atomic\% \\
\hline $\mathrm{C}$ & 13.58 & 40.28 \\
$\mathrm{O}$ & 6.76 & 15.06 \\
$\mathrm{Cu}$ & 79.66 & 44.67 \\
\hline
\end{tabular}

Figure 9. (a) SEM and (b) FESEM images of $\mathrm{Cu}$ 7. The EDS results of (c, e) cubic structure and (d, f) uniform background indicate the presence of copper oxide on the $\mathrm{Cu}$ surface. 
oxide to amorphous carbon on $\mathrm{Cu}$ substrate is 0.57 using Raman bands intensity. Gaussian fitting of the Raman spectra between 1300 and $1700 \mathrm{~cm}^{-1}$ shows an extra band at around $1450 \mathrm{~cm}^{-1}$, which is a sign of trans-polyacetylene and can appear only in grain boundaries of nanostructured carbon coatings [30]. The presence of this band in $\mathrm{Cu} 6 \mathrm{can}$ be a witness to the smaller grain structure of coating than in other samples (figure 5f). The high thermal gradient in bulk electrolyte and vicinity of the cathode during the cooling process leads to formation of smaller bubbles, which causes smaller discharges and nanostructured coating [27]. Thus, it is deduced that for conversion of amorphous carbon to graphitic structure, the substrate temperature and ions and radicals energy and concentration parameters are important. With a greater rise of coating voltage, the carbon structure of coating in $\mathrm{Cu} 6$ can be similar to that in $\mathrm{Cu} 4$. Thus, lower electrolyte temperature is more suitable for the development of a uniform and nanostructured CPE coating. Habazaki et al [31] have studied the effects of electrolyte temperatures for the PEO process and concluded that a uniform and dense coating was developed at lower electrolyte temperature.

\subsection{Effect of anode to cathode surface area}

The effect of anode to cathode surface area on currentvoltage behaviour in the CPE process is studied here by a variation of cathode size while keeping the anode counterpart fixed. Current density vs. voltage is plotted in figure 8 for more accuracy. The bigger substrate surface decreased the current density whereas the voltage at the saturated current is similar for both samples. The smaller size of the cathode leads to a more intense electric field, which results in stronger discharges [12]. The equation reported by Paulmier et al [16] shows the relation between the electric field and anode to cathode size ratio. The stronger discharges increase the local temperature of the substrate. Despite the similar breakdown voltages of both samples, a significantly lower current density of $\mathrm{Cu} 7$ causes the formation of only copper oxide coating, which is confirmed by the absence of D and $\mathrm{G}$ bands in the Raman spectrum (figure 3).

The XRD pattern of this sample shows the presence of copper oxide film on the $\mathrm{Cu}$ substrate. Thus, formation of carbon structure on substrate is negligible by reduction of electric field around the cathode. The SEM image of $\mathrm{Cu} 7$ shows a cubic morphology of coating (figure 9). The energy dispersive spectroscopy (EDS) composition analysis of this cubic structure and its background confirms formation of the $\mathrm{Cu}_{2} \mathrm{O}$ and $\mathrm{CuO}$ on the $\mathrm{Cu}$ surface, respectively. The morphology of $\mathrm{Cu}_{2} \mathrm{O}$ deposited from solution can be controlled by the temperature and solution composition [32,33]. Previous research has shown that the increase of the hydroxide anions concentration in the deposition solution causes cubic morphology of $\mathrm{Cu}_{2} \mathrm{O}$ at lower temperature [34]. The hydroxide anions transfer to cathode surface can be reduced by discharges reduction on the surface using larger cathode. The observation of an extra Raman band around $1800 \mathrm{~cm}^{-1}$ and the pinnacle of Raman bands are two differences between $\mathrm{Cu} 7$ and other samples. The $1800 \mathrm{~cm}^{-1}$ band can be related to formation of the carbonyl groups on the surface [35] because of the presence of carbon, which was shown by the EDS. The pinnacle of Raman bands can be related to copper oxide morphology.

\section{Conclusions}

The cathodic plasma electrolysis process was applied successfully to modify copper surface. The effect of some process parameters such as electrical conductivity, volume and temperature of electrolyte and ratio of anode to cathode surface area on current-voltage variations and subsequently formation of carbon and copper oxide on substrate and also their structure was studied using $50 \mathrm{vol} \%$ ethanol as electrolyte and coating voltage of $150 \mathrm{~V}$. The following conclusions are drawn.

- The reduction of copper oxide content on the $\mathrm{Cu}$ surface from 100 to $45 \mathrm{vol} \%$ and formation of amorphous carbon were observed during an increase of the $V_{\mathrm{b}}-V_{\mathrm{d}}$ interval by electrical conductivity of electrolyte.

- Using a higher electrolyte volume led to an increase of current density from 2 to $4.4 \mathrm{~A} \mathrm{~cm}^{-2}$ by postponing the bubbling phenomenon around the cathode and caused formation of graphitic carbon on the $\mathrm{Cu}$ substrate. The significant decrease of current density led to just oxidation of $\mathrm{Cu}$ substrate in cubic morphology, even at suitable voltage of coating.

- An increase of thermal gradient in bulk electrolyte and vicinity of the cathode during the cooling process of electrolyte led to formation of smaller bubbles, which caused smaller discharges and nanostructured coating.

\section{References}

[1] Gupta P, Tenhundfeld G, Daigle E and Ryabkov D 2007 Surf. Coat. Technol. 2018746

[2] Sreekanth D, Rameshbabu N and Venkateswarlu K 2012 Ceram. Int. 384607

[3] Parfenov E, Yerokhin A, Nevyantseva R, Gorbatkov M, Liang C J and Matthews A 2015 Surf. Coat. Technol. 2692

[4] Yerokhin A, Nie X, Leyland A, Matthews A and Dowey S 1999 Surf. Coat. Technol. 12273

[5] Aliofkhazraei M, Rouhaghdam A S and Gupta P 2011 Crit. Rev. Solid State Mater. Sci. 36174

[6] Yang X, He Y, Wang D and Gao W 2002 Electrochem. SolidState Lett. 533

[7] Tavakoli H, Khoie S M, Marashi S and Bolhasani O $2013 \mathrm{~J}$. Mater. Eng. Perform. 222351

[8] Paulmier T, Bell J M and Fredericks P M 2008 J. Mater. Process. Technol. 208117

[9] Khan R, Yerokhin A, Li X, Dong H and Matthews A 2010 Surf. Coat. Technol. 2051679

[10] Pang H, Wang X, Zhang G, Chen H, Lv G and Yang S 2010 Appl. Surf. Sci. 2566403 
[11] Paulmier T, Bell J M and Fredericks P M 2007 Thin Solid Films 5152926

[12] Al Bosta M, Ma K J and Chien H H 2013 J. Ceram. Article ID 350931 doi: 10.1155/2013/350931

[13] Wei C, Tian X, Yang S, Wang X, Fu R K and Chu P K 2007 Surf. Coat. Technol. 2015021

[14] Guangliang Y, Xianyi L, Yizhen B, Haifeng C and Zengsun J 2002 J. Alloys Compd. 345196

[15] Srinivasan P B, Liang J, Blawert C, Störmer M and Dietzel W 2009 Appl. Surf. Sci. 2554212

[16] Paulmier T, Bell J M and Fredericks P M 2007 Surf. Coat. Technol. 2018771

[17] Debbichi L, Marco de Lucas M, Pierson J and Kruger P 2012 J. Phys. Chem. C 11610232

[18] Niaura G 2000 Electrochim. Acta 453507

[19] Siddiqui H, Qureshi M and Haque F Z 2016 Optik-Int. J. Light Electron. Opt. 1272740

[20] Meletis E, Nie X, Wang F and Jiang J 2002 Surf. Coat. Technol. 150246

[21] Che C, Li Y, Zhang G and Deng D 2014 Open J. Syn. Theor. Appl. 35

[22] Izake E L, Paulmier T, Bell J M and Fredericks P M $2005 \mathrm{~J}$. Mater. Chem. 15300
[23] Wu J, Xue W, Jin X, Wang B, Du J and Wu Z 2013 Appl. Phys. Lett. 103031905

[24] Chu P K and Li L 2006 Mater. Chem. Phys. 96253

[25] Ferrari A C and Robertson J 2004 Phil. Trans. R. Soc. London A 3622477

[26] Krishna L R, Somaraju K and Sundararajan G 2003 Surf. Coat. Technol. 163484

[27] Brennen C E 2013 Cavitation and bubble dynamics (New York, USA: Cambridge University Press)

[28] Mimura K, Lim J W, Isshiki M, Zhu Y and Jiang Q 2006 Metall. Mater. Trans. A 371231

[29] Ferrari A C 2002 Diamond Relat. Mater. 111053

[30] Popov C, Kulisch W, Gibson P, Ceccone G and Jelinek M 2004 Diamond Relat. Mater. 131371

[31] Habazaki H, Tsunekawa S, Tsuji E and Nakayama T 2012 Appl. Surf. Sci. 259711

[32] Zhou G and Yang J C 2003 Appl. Surf. Sci. 210165

[33] Zhao Y, Zhu J J, Hong J M, Bian N and Chen H Y 2004 Eur. J. Inorg. Chem. 20044072

[34] Susman M D, Feldman Y, Vaskevich A and Rubinstein I 2014 ACS Nano 8162

[35] Lambert J B, Shurvell H F, Lightner D A and Cooks R G 1987 Introduction to organic spectroscopy (New York, USA: Macmillan Publishing Company) 